Bangladesh J. Bot. 39(2): 199-205, 2010 (December)

\title{
LOCALIZATION OF 5S rDNA AND 18S-5.8S-25S rDNA PROBES IN CRINUM LATIFOLIUM L. GENOME
}

\author{
Sheikh Shamimul Alam*, Md Yahia Zaman and Md Shahidur Rahman \\ Department of Botany, University of Dhaka, Dhaka-1000, Bangladesh
}

Key words: rDNA FISH, Crinum latifolium

\begin{abstract}
Two conserved repeats viz. 5S rDNA and 18S-5.8S-25S rDNA were used as probes for physical mapping in the genome of Crinum latifolium L. $(2 n=3 X=33)$. Nine out of $115 S$ rDNA signals were found in three chromosomes of group VI at metaphase. The 5S rDNA gene array were not AT-rich. Four 18S-5.8S$25 \mathrm{~S}$ rDNA signals at interphase, prophase and metaphase showed their stable nature. The contraction and expansion of these signal regions proved the euchromatic nature of 18S-5.8S-25S rDNA. The 5S rDNA and the 18S-5.8S-25S rDNA signals provided useful cytogenetic markers for C. latifolium genome. Patterns of $5 S$ rDNA signals suggested the possible structural aberration in the genome. Although the 5S rDNA sites suggested C. latifolium as autotriploid, 18S-5.8S-25S rDNA sites did not conclude anything about the nature of genome. Unequivocal determination of the nature of genome in C. latifolium remained unanswered.
\end{abstract}

\section{Introduction}

A number of species of the genus Crinum L. (Amaryllidaceae) collected from different regions of Bangladesh were considered in the past to study its cytogenetics (Akhter et al. 1992, Patwary and Zaman 1975, Patwary and Zaman 1978, Patwary and Zaman 1981, Zaman et al. 1977 a, b). Alam et al. (1991) reported that Crinum defixum and C. pratense have very few morphological differences with $2 n=22$ chromosomes. They differentiated these two species by comparative karyotype analysis. Later Alam et al. (1998) carried out fluorescent banding technique with two commonly used fluorochrome dye viz. CMA and DAPI to distinguish the karyotypes of Crinum defixum and C. pratense. They reported that differential CMA- and DAPIbands were species specific. Lubna et al. (2004) also found that fluorescent banding was quite suitable for distinguishing the karyotypes of some spp. of Crinum. But physical location of a particular DNA segment was not possible using this method. Molecular cytogenetics is a strong tool to study the organization of different repeats of the genomes. Repetitive sequence families are major component of plant genomes (Heslop-Harrison 2000). In genomic organizations, repeats are divided into tandemly arranged and dispersed sequences (Schmidt and Heslop-Harrison 1998). Tandem repeats are divided into satellite DNA, micro- and mini- satellites, telomeric repeats and ribosomal genes. Typical plant satellite DNA repeats range in size between 160 - 180 bp or 320 $360 \mathrm{bp}$ and are organized in tandem arrays with up to $10^{5}$ copies per haploid genome (Hemleben et al. 2000). The most conserved tandemly arranged sequences are ribosomal RNA genes in eukaryotes comprising of 18S-5.8S-25S rDNA repeating units forming long arrays. Fluorescent in situ hybridization (FISH) has been widely used to localize rDNA gene arrays on plant chromosomes (Leitch and Heslop-Harrison 1992, Schmidt et al. 1994). Both the 5S rDNA and the 18S-5.8S-25S rDNA genes provide useful markers for chromosome identification and karyotyping (Doudrick et al. 1995, Brown et al. 1999, Begum et al. 2009).

A number of steps and chemicals are involved in FISH and thus, the procedure is expensive and time consuming. Hydrolyzing with enzyme mixture is one of the expensive steps in this technique. If this step could be replaced by another easier one, it would save money and time both.

*Corresponding author: E-mail: <ssalam81@yahoo.com> 
In the present study, an attempt was undertaken for the first time in Bangladesh to construct a physical map in the genome of Crinum latifolium. Here two different highly conserved repeats viz. 5S rDNA and 18S-5.8S-25S rDNA (complex) were used as probes. Moreover an alternative procedure for hydrolysis was tried. The aims of this molecular cytogenetic research were (i) to develop an alternative hydrolysis procedure, (ii) to construct the physical map with the above mentioned probes and (iii) characterize the karyotype of Crinum latifolium L.

\section{Materials and Methods}

Crinum latifolium L. grown in the Botanic Garden, Department of Botany, University of Dhaka was used. Roots were collected and washed in running tap water for 4 - $5 \mathrm{~m}$. After removal of excess water, roots were pretreated with PDB for six h at room temperature $\left(28-30^{\circ} \mathrm{C}\right)$ and fixed in $45 \%$ acetic acid for $15 \mathrm{~m}$ at $4^{\circ} \mathrm{C}$. Both squash and dropping method were used for chromosome preparation. In case of squash method, the RTs were over hydrolyzed for $1 \mathrm{~m}$ and squashed with $45 \%$ acetic acid. The cover glasses were removed quickly and air dried for at least $48 \mathrm{~h}$ before study. For dropping method, procedure of Schwarzacher and Heslop-Harrison (2000) was followed with slight modification. Briefly, fixed roots were washed in enzyme buffer (0.01 M citric acid - sodium citrate, $\mathrm{pH} 4.6$ ) to remove the fixative and digested at $37^{\circ} \mathrm{C}$ for $1 \mathrm{~h} 20 \mathrm{~m}$ in enzyme solution consisting of $2.5 \%$ pectinase, $2.5 \%$ cellulase, $2.5 \%$ pectolyase and $1.0 \%$ cytohelicase in enzyme buffer.

The clone pXV1 (Schmidt et al. 1994) containing the 5S rRNA gene from Beta vulgaris was labelled with biotin-16-dUTP using PCR while the clone pTa71 from Triticum aestivum (Gerlach and Bedbrook 1979) consisting of a large part of the 18S-5.8S-25S rRNA genes was labelled with digoxigenin-11-dUTP by nick translation.

FISH was performed according to Heslop-Harrison et al. (1991) with minor modification. Chromosome spreads were pre-treated with $100 \mu \mathrm{L}^{-1}$ RNase A in $2 \times$ sodium saline citrate $(2 \times$ SSC) for $1 \mathrm{~h}$ at $37^{\circ} \mathrm{C}$ and washed twice in $2 \times$ SSC. After incubation with $10 \mu \mathrm{g} \mathrm{mL}{ }^{-1}$ pepsin in $0.01 \mathrm{mM} \mathrm{HCl}$ for $20 \mathrm{~min}$ at $37^{\circ} \mathrm{C}$, preparations were stabilized in freshly de-polymerized $4 \%$ $(\mathrm{w} / \mathrm{v})$ paraformaldehyde in water for 10 min, dehydrated in a graded ethanol series and air dried. The hybridization mixture consisting of $50-150 \mathrm{ng} \mathrm{LL}^{-1}$ of DNA probe, $50 \%(\mathrm{v} / \mathrm{v})$ formamide, $10 \%(\mathrm{w} / \mathrm{v})$ dextran sulfate, $0.1 \%$ sodium dodecyl sulfate (SDS) and $300 \mathrm{ng} \mathrm{LL}^{-1}$ of sheared salmon sperm DNA in $2 \times \mathrm{SSC}$, was incubated for $10 \mathrm{~min}$ at $70^{\circ} \mathrm{C}$ and chilled on ice. Then $30 \mu \mathrm{L}$ of the hybridization mixture was added to the chromosome preparations and covered with a plastic coverslip. The hybridization mixture and the chromosomal DNA were denatured at $70^{\circ} \mathrm{C}$ for $5 \mathrm{~m}$. The temperature was gradually decreased to $55,50,45$ and finally $37^{\circ} \mathrm{C}$ using different water baths. Hybridization was carried out overnight at $37^{\circ} \mathrm{C}$. Following hybridization, the slides were washed stringently in $20 \%(\mathrm{v} / \mathrm{v})$ formamide in $0.1 \times \mathrm{SSC}$ at $42^{\circ} \mathrm{C}$ to remove mismatched or unhybridized probe molecules. For the detection of digoxigenin- or biotin labelled probes, slides were equilibrated in $4 \times \mathrm{SSC} / 0.1 \%(\mathrm{v} / \mathrm{v})$ Tween 20 and blocked in $5 \%(\mathrm{w} / \mathrm{v})$ bovine serum albumin in $4 \times \mathrm{SSC} / 0.1 \%(\mathrm{v} / \mathrm{v})$ Tween 20 for $5 \mathrm{~min}$. Slides were incubated with a final concentration of $2 \mu \mathrm{g} \mathrm{mL} \mathrm{m}^{-1}$ of sheep antidigoxigenin antibody conjugated with fluorescein isothiocyanate (FITC) or streptavidin-Cy3 in a moist chamber at $37^{\circ} \mathrm{C}$ for $1 \mathrm{~h}$. Excess antibody was removed by washing the slides in $4 \times \mathrm{SSC} / 0.1 \%(\mathrm{v} / \mathrm{v})$ Tween 20 three times each for $5 \mathrm{~min}$. After counterstaining with DAPI (4, 6-diamidino-2-phenylindole; $2 \mu \mathrm{g} \mathrm{mL} \mathrm{m}^{-1}$ ), the slides were mounted in antifade solution (AF1, Citifluor). Examination of slides was carried out with fluorescent microscope (HUND, Germany) equipped with filters for FITC, Cy3 and DAPI. Images were acquired directly with Applied Spectral Imaging v.3.3 software, coupled with a high- 
resolution camera (Canon), and printed from Adobe Photoshop after contrast optimization using only functions affecting the whole image equally.

\section{Results and Discussion}

Squash method versus enzymatic method: Generally during FISH, chromosomes are hydrolyzed with an enzyme mixture which contains various enzymes in different proportions such as pectinase (5\%), cellulase (4\%), cytohelicase (2\%) and pectolyase $(0.5 \%)$. The enzyme mixture helps to digest the cell wall composed of pectin and cellulose. As a result, the chromosomes become free and the chemical can bind easily with it. This method is very effective however, requires a huge amount of materials for digestion and is therefore costly.

An alternative method for hydrolysis was tried in this present work. Here an individual root was over hydrolyzed (about $1 \mathrm{~m}$ ) in a mixture of $1 \mathrm{~N} \mathrm{HCl}$ and $45 \%$ acetic acid $(2: 1)$. After squashing, the cell wall bursts. As a consequence chromosomes become almost free from cytoplasm. This hydrolyzing method gave similar result to that of enzymatic hydrolysis method (Figs 2, 6). This method is quicker, less expensive and useful even with a single root. Therefore, this hydrolyzing method stands as a new technique for chromosome preparation during FISH.

5S rDNA FISH: In this work, 11 signals were frequently found in most of the cells. Out of 11 signals, 9 were present in 3 members of group VI (Fig. 4). The remaining two very small signals were found in a member of group I and X (Fig. 4). The occurrence of signals reveal that almost all 5s rDNA repeats are distributed in group VI.

The 11 signals were observed in almost every interphase nuclei (Fig. 1). However, in very rare cases less number of signals were found. The later signals were bigger than the earlier ones (Fig. 4). This finding indicates that 5S rDNA repeats were aggregated and thus, formed bigger and fewer numbers of signals at interphase.

DAPI is a fluorochrome that binds to the AT-rich repeats of chromosomes fluorescing characteristic blue colour (Schweizer 1976, Alam and Kondo 1995). In the interphase nuclei, a number of blue fluorescing regions indicated the presence of AT-rich repeats. The 5S rDNA signals did not correlate with those blue fluorescing regions (Fig. 1). These signals were far apart from the blue fluorescing regions. This observation suggested that $5 \mathrm{~S}$ rDNA repeats were at least not AT-rich if not rich in GC base pairs (Souza et al. 2008).

FISH has been widely used to localize rDNA gene arrays on plant chromosomes (Leitch and Heslop-Harrison 1992, Schmidt et al. 1994). The 5S rDNA gene provides useful markers for chromosome identification and karyotyping (Doudrick et al. 1995, Brown et al. 1999). Thus the $115 \mathrm{~S}$ rDNA signals would be used as markers for the respective chromosomes.

18S-5.8S-25S rDNA FISH: Four green fluorescing signals were found in the metaphase chromosomes (Fig. 7). Due to much overlapping and lack of available materials (available only in the rainy season) it was not possible to prepare the karyotype. However, it was clear that the four signals were present in four different chromosomes. Four signals were also found in the interphase nuclei and prophase chromosomes (Figs 5, 6) indicating the stable position throughout the cell cycle.

The signals were small and spherical in the interphase nuclei and metaphase chromosomes but elongated in the prophase chromosomes (Figs 5-7). The chromatins are usually condensed at the interphase and contracted at metaphase, however, extended at prophase. The 18S-5.8S-25S rDNA probe is actually complementary sequence to the nucleolar organizing region (NOR) (Souza et al. 2008). NOR is composed of euchromatins and thus, transcribe to rRNA. The contraction and extension of signal regions at different stages of cell division clearly indicating the euchromatic nature of 18S-5.8S-25S rDNA. 
The total length of the four signals was about $4.63 \mu \mathrm{m}$. This length was smaller than the total length of 5S rDNA signals (Table 1). 18S-5.8S-25S rDNA represents NOR region. The NOR regions are limited and localized in certain position of chromosomes in a genome (Schweizer 1976, Schmidt et al. 1994). On the other hand, 5S rDNAs are dispersed repeats and distributed all along the genome. As a result, the total length of $5 \mathrm{~S}$ rDNA should be bigger than that of $18 \mathrm{~S}-5.8 \mathrm{~S}-$ $25 \mathrm{~S}$ rDNA.
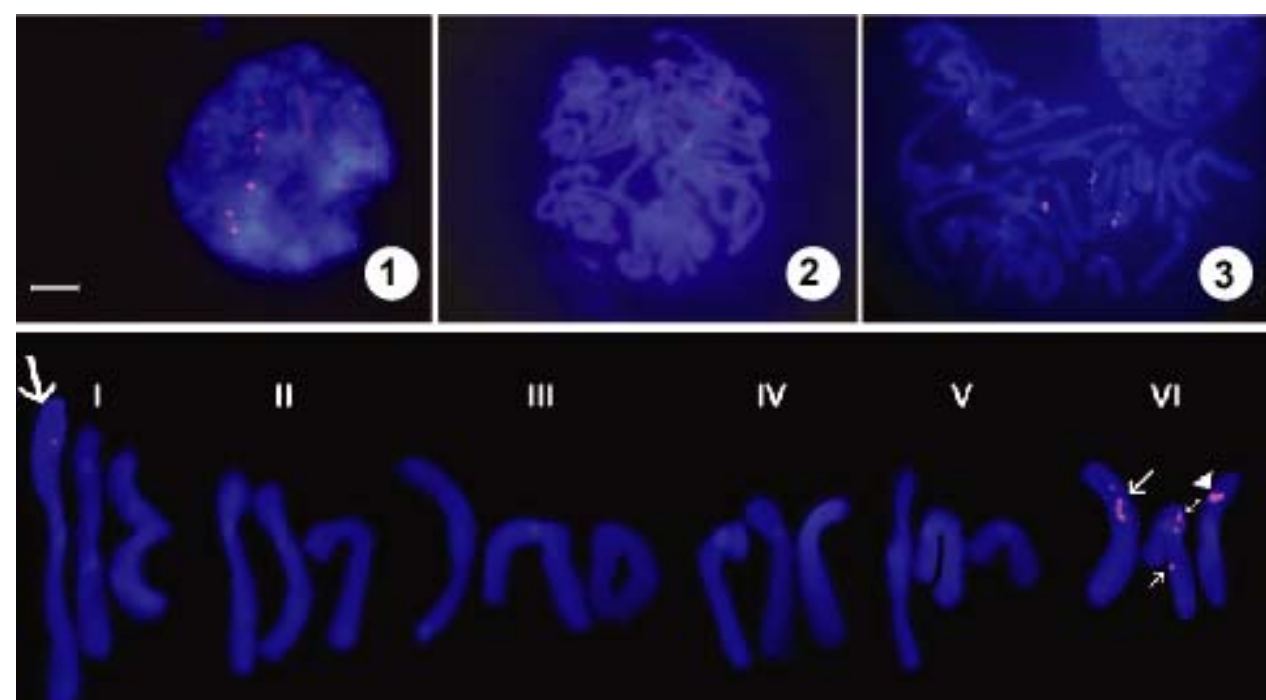

II

III

IV

$\checkmark$

VII

VIII

$\mathbf{I X}$

$\mathbf{x}$

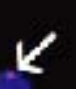

$\mathbf{X I}$
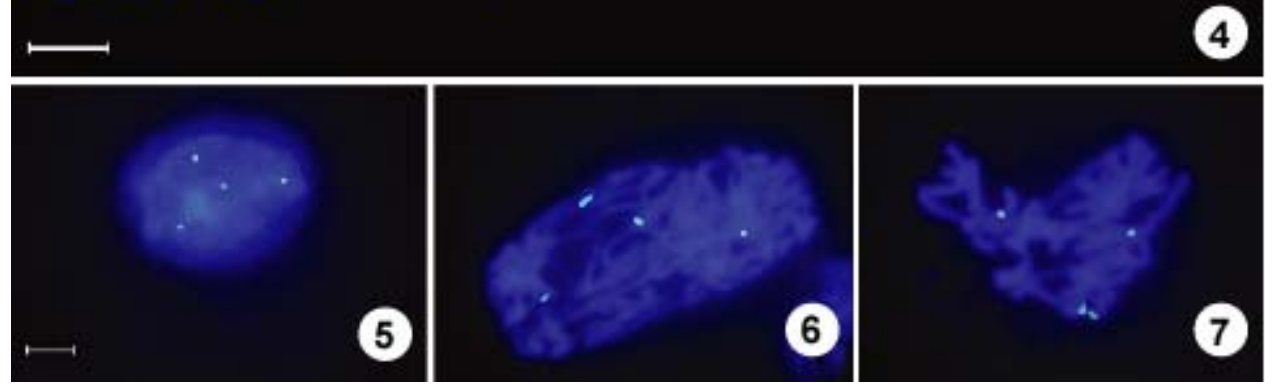

Figs 1-7. FISH with 5S rDNA and 18S-5.8S-25S rDNA probes in Crinum latifolium: 1 . 5S rDNA FISH in interphase nuclei, 2. 5S rDNA FISH in prophase chromosomes, 3. 5S rDNA FISH in metaphase chromosomes, 4. Karyotype prepared from 5S rDNA FISH of mitotic metaphase chromosomes, 5. 18S5.8S-25S rDNA FISH in interphase nuclei, 6. 18S-5.8S-25S rDNA FISH in prophase chromosomes, 7. 18S-5.8S-25S rDNA FISH of mitotic metaphase chromosomes. Bars $=10 \mu \mathrm{m}$.

The chromosomes of $C$. latifolium have a characteristic number and position of rDNA sites. Therefore, the 5S- and 18S-5.8S-25S rDNA provide useful cytogenetic markers for unequivocal physical mapping in its karyotype. 
Nature of genome in C. latifolium: The karyotype of C. latifolium clearly indicated that this species is a triploid ( $2 \mathrm{n}=3 \mathrm{X}=33$, Lubna et al. 2004). A question was raised earlier as to whether this species was an auto- or allotriploid. Lubna et al. (2004) tried to determine the nature of genomes present in C. latifolium by differential fluorescent banding. On the basis of similar banding pattern in all three members a of certain group, they suggested this species to be autotriploid. However, different banding patterns among three members of another group, identify the species to be allo-triploid. Therefore, a confusion regarding the quality of genomes in this species still exist.

Table 1. Comparative analysis of 5S rDNA and 18S-5.8S-25S rDNA FISH on Crinum latifolium chromosomes.

\begin{tabular}{lccccc}
\hline Probes & $\begin{array}{c}\text { No. of } \\
\text { signals }\end{array}$ & $\begin{array}{c}\text { No. of chromo- } \\
\text { somes showed } \\
\text { signals }\end{array}$ & $\begin{array}{c}\text { No. of chromo- } \\
\text { somes showed } \\
\text { multiple signals }\end{array}$ & $\begin{array}{c}\text { Total length } \\
\text { of signals } \\
(\mu \mathrm{m})\end{array}$ & $\begin{array}{c}\text { \% of } \\
\text { repeats in the } \\
\text { genome }\end{array}$ \\
\hline 5S rDNA & 11 & 5 & 3 & 10.53 & 1.58 \\
18S-5.8S-25S rDNA & 4 & 4 & - & 4.63 & 0.696 \\
\hline
\end{tabular}

In the present study, one member of group VI had four signals on the short arm (Fig. 4, big arrow). The second member of this group had in total three of which two signals were on the short arm and another on the long arm (Fig. 4, small arrow). A pair of signals was found on the short arm in the third member of this group (Fig. 4, arrow head). It indicated that the 3 chromosomes of this group possessed different numbers of signal i.e. one member of this group had four, another member three (in two different sites) and the remaining member had two signals. In addition to this group, one very low signal was found in only a member of group I and X (Fig. 4, thick arrow).

If C. latifolium is considered as auto-triploid, each member of group VI should have four signals (since it was the maximum number). Moreover, there should not be any signal in only a member of group I and X. The reason for different signal numbers on different chromosomes of group VI and presence of one signal in only a member of group I and X are not clear. However, the number and distribution of signals provided the following assumptions: (i) due to occurrence of translocation between a member of group VI with a member of group I and X two rDNA sites from a member of group VI translocated to a member of group I and X. Thus, only two signals were present in that member of group VI (Fig. 4, arrow head) and (ii) due to deletion of a rDNA site from another chromosome of group VI and occurrence of a paracentric inversion in the same chromosome, one rDNA site was absent and another shifted to another arm of the same chromosome (Fig. 4, arrow head). As a result this chromosome had three signals of which two in short arm and another in long arm. However, ignoring these structural changes (translocation, deletion and paracentric inversion) it could be suggested that the three chromosomes of group VI are homologous (except the aberrated regions) and in this regard C. latifolium may be considered as an autotriploid.

In contrast, the four 18S-5.8S-25S rDNA signals occurred on four different chromosomes (Fig.7). If this species is an autotriploid there must be three or multiple of three signals in homologous members in a group. Why instead of three, four equal signals were found in four different chromosomes is not clear with the data available. Therefore, the nature of genomes in $C$. latifolium remains unanswered. 


\section{Acknowledgements}

The authors are grateful to Dr Rabeya Begum for her technical assistance. Sincere thank to Prof. Dr Thomas Schmidt, Technical University of Dresden, Germany for providing the labeled probes and other supports. Deep gratitude is due to Prof. Dr M Akhtaruzzaman (passed away recently), Department of Botany, University of Dhaka for going through the manuscript. They are grateful to the Alexander Von Humboldt Foundation for kindly providing Fluorescent microscope and other necessary instruments.

\section{References}

Akhter S, SkS Alam, MA Zaman and MU Patwary 1992. Intraspecific variation in chromosome morphology of Crinum latifolium. Bangladesh J. Bot. 21(1): 73-79.

Alam SkS, MA Zaman, S Akhter and MU Patwary 1991. Karyotype analysis of Crinum defixum Ker-Gawl and Crinum pratense Herb. Bangladesh J. Bot. 20(1): 1-6.

Alam SkS, SS Azhar, RH Sarker and MA Zaman 1998. Karyotype analysis with different banding in Crinum pratense and Crinum defixum. Cytologia 63: 223-227.

Alam SkS and K Kondo 1995. Differential staining with orecein, Giemsa, CMA and DAPI for comparative chromosome study of 12 species of Australian Drosera (Droseraceae). Amer. J. Bot. 82(10): 1278-1286.

Begum R, SkS Alam, G Menzel and T Schmidt 2009. Comparative molecular cytogenetics of major repetitive sequence families of three Dendrobium species (Orchidaceae) from Bangladesh. Ann. Bot. 104: 863-872.

Brown SE, JL Stephens, NLV Lapitan and DL. Knudson 1999. FISH landmarks for barley chromosomes (Hordeum vulgare L.). Genome 42: 274-281.

Doudrick RL, JS Heslop-Harrison, CD Nelson, T Schmidt, WL Nance and T Schwarzacher 1995. Karyotype of Slash Pine (Pinus elliottii var. elliottii) using patterns of fluorescence in situ hybridization and fluorochrome banding. Heredity 86: 289-296.

Gerlach WL and JR Bedbrook 1979. Cloning and characterization of ribosomal RNA genes from wheat and barley. Nucleic Acids Res. 7: 1869-1885.

Heslop-Harrison JS, T Schwarzacher, K Anamthawat-Jonsson, AR Leitch, M Shi and IJ Leitch 1991. In situ hybridization with automated chromosome denaturation. Technique 3: 109-116.

Heslop-Harrison JS 2000. Comparative genome organization in plants: from sequence and markers to chromatin and chromosomes. Plant Cell 12: 617-636.

Hemleben V, T Schmidt, RA Torres-Ruiz and U Zentgraf 2000. Molecular cell biology: role of repetitive DNA in nuclear architecture and chromosome structure. Progress Bot. 61: 91-117.

Leitch IJ and JS Heslop-Harrison 1992. Physical mapping of the 18S-5.8S-26S rRNA genes in barley by in situ hybridization. Genome 35: 1013-1018.

Lubna A, R Begum, SS Noor, MA Zaman and SkS Alam 2004. Reversible fluorescent chromosome banding in three Crinum spp. (Amaryllidaceae). Cytologia 69(1): 69-74.

Patwary MU and MA Zaman 1975. Cytogenetics of Amaryllidaceae. III. Karyomorphology of wild Crinum amoenum Roxb. - A new cytotype. J. Asiatic Soc. Bangladesh (Sci.) 1(1): 11-15.

Patwary MU and MA Zaman 1978. Cytogenetics of Amaryllidaceae. VII. Karyomorphology of wild Crinum wattii Baker - A basic diploid. J. Bangladesh Acad. Sci. 2 : 101-104.

Patwary MU and MA Zaman 1981. Cytogenetics of Amaryllidaceae. VIII. Karyomorphology and meiotic behaviour of Crinum zeylanicum L. - a new cytotype. Cytologia 46 : 141-148.

Schwarzacher T and Heslop-Harrison JS 2000. Practical in situ hybridization. Oxford: BIOS Scientific Publishers Ltd., Oxford.

Schweizer D 1976. Reverse fluorescent chromosome banding with Chromomycin and DAPI. Chromosoma 58: 307-324. 
Schmidt T, T Schwarzacher and J Heslop-Harrison 1994. Physical mapping of rRNA genes by fluorescent in situ hybridization and structural analysis of 5S rRNA genes and intergenic spacer sequences in sugar beet (Beta vulgaris). Theo. App. Genet. 88: 629-636.

Schmidt T and JS Heslop-Harrison 1998. Genomes, genes and junk: the large-scale organization of plant chromosomes. Trends Plant Sci. 3: 195-199.

Souza IL, LK Santos-Silva, PC Venere and O Moreira-Filho 2008. Molecular cytogenetics of Salminus fish (Characiformes) based on 5S and 18S rRNA genes hybridization, fluorochrome staining and C-banding. Micron 39(7): 1036-1041.

Tanaka R 1971. Type of resting nuclei in Orchidaceae. Bot. Mag. Tokyo 84: 118-122.

Zaman MA, MU Patwary and BN Chakraborty 1977a. Cytogenetics of Amaryllidaceae. IV. Karyomorphology and meiotic behaviour of wild Crinum stenophyllum Baker. Bangladesh J. Bot. 6(12): 73-78.

Zaman MA, BN Chakraborty and MU Patwary 1977b. Cytogenetics of Amaryllidaceae. V. Karyomorphology and meiotic behaviour of wild Crinum asiaticum L. Dhaka Univ. Stud. 24(2): 55-61.

(Manuscript received on 30 October, 2010; revised on 6 November, 2010) 